\title{
Effect of milnacipran on body weight in patients with fibromyalgia
}

This article was published in the following Dove Press journal:

International Journal of General Medicine

17 October 2012

Number of times this article has been viewed

\author{
Lesley M Arnold' \\ Robert H Palmer ${ }^{2}$ \\ Michael R Hufford ${ }^{3}$ \\ Wei Chen ${ }^{2}$ \\ 'Department of Psychiatry and \\ Behavioral Neuroscience, University \\ of Cincinnati College of Medicine, \\ Cincinnati, $\mathrm{OH},{ }^{2}$ Medical Affairs, \\ Forest Research Institute Inc, \\ Jersey City, NJ, ${ }^{3}$ Clinical Development, \\ Cypress Bioscience Inc, San Diego, \\ CA, USA
}

Correspondence: Lesley M Arnold University of Cincinnati College of Medicine, Medical Arts Building, 222 Piedmont Avenue, Suite 8200, Mail Location 665S, Cincinnati, $\mathrm{OH} 45219$, USA

$\mathrm{Tel}+\mathrm{I} 5 \mathrm{I} 34758 \mathrm{II} 0$

Fax +I 5134758116

Email lesley.arnold@uc.edu
Background: The purpose of this study was to evaluate the effects of milnacipran on body weight in patients with fibromyalgia.

Methods: Analyses were conducted in the following groups: patients from three doubleblind, placebo-controlled milnacipran trials ( 3 months, $\mathrm{n}=2096$; 6 months, $\mathrm{n}=1008$ ); 354 patients receiving milnacipran in placebo-controlled trials and double-blind extension studies (total $\geq 12$ months of treatment); and 1227 patients in a long-term (up to 3.25 years) open-label milnacipran study.

Results: In placebo-controlled trials, $77 \%$ of patients were overweight or obese at baseline (body mass index $\geq 25 \mathrm{~kg} / \mathrm{m}^{2}$ ). Mean weight loss was found with milnacipran at 3 months (100 mg/day, $-1.14 \mathrm{~kg} ; 200 \mathrm{mg} /$ day, $-0.97 \mathrm{~kg}$; placebo, $-0.06 \mathrm{~kg} ; P<0.001)$ and 6 months $(100 \mathrm{mg} /$ day, $-1.01 \mathrm{~kg} ; 200 \mathrm{mg} /$ day, $-0.71 \mathrm{~kg} ;$ placebo, $-0.04 \mathrm{~kg} ; P<0.05)$. Approximately twice as many milnacipran-treated patients had $\geq 5 \%$ weight loss from baseline compared with placebo ( 3 and 6 months, $P<0.01$ ). In extension studies, mean weight loss in patients receiving $\geq 12$ months of milnacipran was $-1.06 \mathrm{~kg}$. In patients receiving $\geq 3$ years of treatment in the open-label study, mean changes at $12,24,30$, and 36-38 months were $-1.16,-0.76,-0.19$, and $+0.11 \mathrm{~kg}$, respectively. Among milnacipran-treated patients, rates of nausea (the most common adverse event) were lower among patients who lost weight than among those who did not ( 3 months, $P=0.02$ ). Conclusion: The majority of patients with fibromyalgia in the milnacipran studies were overweight or obese. Milnacipran was associated with mean weight loss at 3 and 6 months $(P<0.05$ versus placebo) and at 12 and 24 months of treatment, with mean changes drifting back to baseline at 30 months $(-0.19 \mathrm{~kg})$ and $36-38$ months $(+0.11 \mathrm{~kg}$, no placebo comparison).

Keywords: fibromyalgia, milnacipran, body weight

\section{Introduction}

Fibromyalgia is a multisymptomatic pain disorder often accompanied by additional health problems, including comorbid pain disorders, psychiatric illness, and/or chronic medical conditions. ${ }^{1-3}$ A reported $32 \%-50 \%$ of patients with fibromyalgia are obese (body mass index $[\mathrm{BMI}] \geq 30$ ), and $21 \%-30 \%$ are overweight $(\mathrm{BMI} \geq 25) .{ }^{4-9}$ Higher BMIs in patients with fibromyalgia have been significantly correlated with decreased physical functioning, reduced quality of life, increased pain sensitivity, and sleep problems. ${ }^{4,6-10}$

Several factors may contribute to the relationship between fibromyalgia and obesity. ${ }^{11}$ First, some pathophysiologic abnormalities found with fibromyalgia are also associated with obesity, such as dysregulation of the hypothalamic-pituitary axis, hormonal imbalances, and increased sensitivity to pain. ${ }^{7,8}$ In addition, obesity 
may exacerbate pain by increasing pressure on joints, possibly leading to more limited physical activity and weight gain. ${ }^{12}$ Comorbid depression or other psychiatric disorders commonly associated with obesity may also contribute to weight gain in patients with fibromyalgia. ${ }^{11,13}$ Finally, weight gain can result from medications used to manage symptoms of fibromyalgia and/or treat comorbid conditions. ${ }^{14,15}$

Pregabalin, duloxetine, and milnacipran are currently approved medications for the management of fibromyalgia. Potentially clinically significant changes $(\geq 7 \%$ change from baseline) have been reported for these medications. In placebo-controlled studies (13-14 weeks), ${ }^{16,17}$ 9\%-15\% of patients with fibromyalgia receiving pregabalin experienced potentially clinically significant weight gain; mean weight changes were not reported. In a pooled analysis of placebo-controlled fibromyalgia trials with duloxetine ( $\leq 3$ months), ${ }^{18}$ mean weight changes with duloxetine and placebo were $-0.87 \mathrm{~kg}$ and $+0.01 \mathrm{~kg}$, respectively $(P \leq 0.001)$. Potentially clinically significant changes were as follows for duloxetine and placebo, respectively: weight loss, $3.0 \%$ and $0.8 \%(P<0.05)$; weight gain, $0.9 \%$ and $1.4 \%$ (nonsignificant). Mean weight gain $(+0.68 \mathrm{~kg})$ was found in duloxetine-treated patients who continued into non-placebocontrolled extension studies ( $>12$ months), with $8.8 \%$ and $16.0 \%$ of patients experiencing potentially clinically significant weight loss and gain, respectively.

Mean weight loss $(-0.7$ to $-1.8 \mathrm{~kg})$ was found in patients with fibromyalgia receiving milnacipran in placebocontrolled trials (3-6 months), ${ }^{19-21}$ with more patients experiencing potentially clinically significant weight loss (2.8\% to $10.4 \%)$ than gain $(1.0 \%$ to $3.0 \%$, data on file, Forest Laboratories Inc). Mean weight loss ( -0.6 to $-1.0 \mathrm{~kg})$ was also found in milnacipran-treated patients who entered an extension study and received 12 total months of active treatment. ${ }^{22}$ The present set of analyses was conducted to investigate further the effects of milnacipran on weight in patients with fibromyalgia receiving short-term and longterm treatment. In addition to examining the effects of baseline BMI, treatment response, and nausea on body weight in a large sample of patients with fibromyalgia pooled from the three placebo-controlled trials of milnacipran, ${ }^{19-21}$ this report presents the following: pooled results from patients in double-blind extension studies who received $\geq 12$ months of continuous milnacipran treatment ${ }^{22,23}$ and the findings from a long-term, open-label study that was conducted in patients who had participated in a previous milnacipran study. ${ }^{24}$ Analyses of data from a subset of patients who received $\geq 3$ years of treatment in the open-label study were also conducted to evaluate the long-term effects of milnacipran on body weight.

\section{Materials and methods Overview of studies}

Pooled data from three placebo-controlled studies ${ }^{19-21}$ in patients meeting 1990 American College of Rheumatology criteria for fibromyalgia ${ }^{25}$ were analyzed to evaluate the effects of milnacipran on body weight at 3 and 6 months. Study designs and methods for these three studies have been previously published. Study 1 was a 6-month trial of milnacipran 100 or $200 \mathrm{mg} /$ day versus placebo that reported 3-month and 6-month outcomes. ${ }^{19}$ Study 2 was a 3-month trial that also investigated milnacipran 100 or $200 \mathrm{mg} /$ day versus placebo. Although this study was designed to evaluate 3-month outcomes, a subset of patients continued treatment for up to 6 months. ${ }^{20}$ Study 3 was a 3-month trial that explored the safety and efficacy of milnacipran $100 \mathrm{mg} /$ day. ${ }^{21}$ The current report includes analyses in patients who had available weight data at baseline $(n=3104)$, at 3 months $(n=2096)$, and at 6 months $(\mathrm{n}=1008)$.

Analyses were also conducted in 354 patients who received milnacipran during lead-in and extension studies ${ }^{22,23}$ and received $\geq 12$ total months of continuous treatment, as well as 1227 patients in a 3-year, open-label, flexible-dosing study with milnacipran ${ }^{24}$ who had participated in a prior placebo-controlled trial or extension study. To be as comprehensive as possible, additional analyses were conducted in 220 patients who received $\geq 3$ years of treatment in the open-label study (ie, patients who reached the final study visit at 36-38 months).

Patients in placebo-controlled and extension studies were required to discontinue centrally acting medications used to manage fibromyalgia symptoms, such as antidepressants, anticonvulsants, opioids, and muscle relaxants. However, such medications were allowed in the open-label study, with the exception of antidepressants that inhibit serotonin and/or norepinephrine reuptake. Weight-related interventions were not specifically prohibited in the milnacipran studies, and a few patients included in the 3-month, 6-month, and 12-month weight analyses $(<1 \%)$ reported taking antiobesity drugs such as phentermine or orlistat; antiobesity drug use was slightly higher in the open-label study ( $1.1 \%$ of patients). Other medications commonly associated with weight change, such as diabetic therapies, corticosteroids, or beta-blockers, ${ }^{14,15}$ were also allowed in the milnacipran studies. 


\section{Statistical analyses}

Analyses were conducted on intent-to-treat populations based on observed cases, except where indicated otherwise. Least squares mean changes in weight were analyzed using analysis of covariance, with treatment group and study center as factors and baseline value as a covariate.

Analysis of covariance was also used to analyze weight changes in patients stratified by baseline BMI ( 3 months) and in treatment responders and nonresponders ( 3 and 6 months). Baseline BMI strata were based on World Health Organization categories, ie, underweight/normal weight (BMI $<25 \mathrm{~kg} / \mathrm{m}^{2}$ ), overweight (BMI 25 to $<30 \mathrm{~kg} / \mathrm{m}^{2}$ ), and obese $\left(\mathrm{BMI} \geq 30 \mathrm{~kg} / \mathrm{m}^{2}\right) .{ }^{26}$ Treatment responders were patients with $\geq 30 \%$ improvement in visual analog scale pain scores and Patient Global Impression of Change rating of "very much improved" or "much improved". Pearson correlations between changes in weight and pain were analyzed in patients receiving $\geq 3$ years of milnacipran treatment in the open-label study.

For overweight and obese patients, $\geq 5 \%$ weight loss is considered a clinically relevant cutoff for controlling cardiovascular and other risk factors ${ }^{27,28}$ and is used to determine significant weight loss in obesity trials. ${ }^{29}$ Given the many overweight/obese patients found in milnacipran studies (see Results), $\geq 5 \%$ weight changes were analyzed for the placebo-controlled ( 3 and 6 months), extension ( $\geq 12$ months), and open-label ( $\geq 3$ years) studies. Chi-square tests were used to compare $\geq 5 \%$ weight changes with milnacipran versus placebo, as well as the incidence of nausea in milnacipran-treated patients who did and did not experience weight loss.

All hypothesis tests were two-sided, with a significance level of 0.05 . Descriptive statistics are presented for 12-month and 3-year patient populations.

\section{Results}

\section{Patients}

Demographics of patients in the three placebo-controlled trials were similar across treatment groups. ${ }^{19-21}$ Most were female (95.8\%) and white (92.7\%), with a mean age of 49.6 years. In the 3104 patients with available baseline weight data from these studies, mean baseline body weight was $82.4 \mathrm{~kg}$ and mean BMI was $30.7 \mathrm{~kg} / \mathrm{m}^{2}$. Based on World Health Organization criteria, ${ }^{26} 77 \%$ of patients in these studies were classified as overweight or obese at baseline, with $49 \%$ of patients in the obese category (Figure 1). Similar demographics were found in patients who continued into extension studies $^{22,23}$ and the open-label milnacipran study. ${ }^{24}$

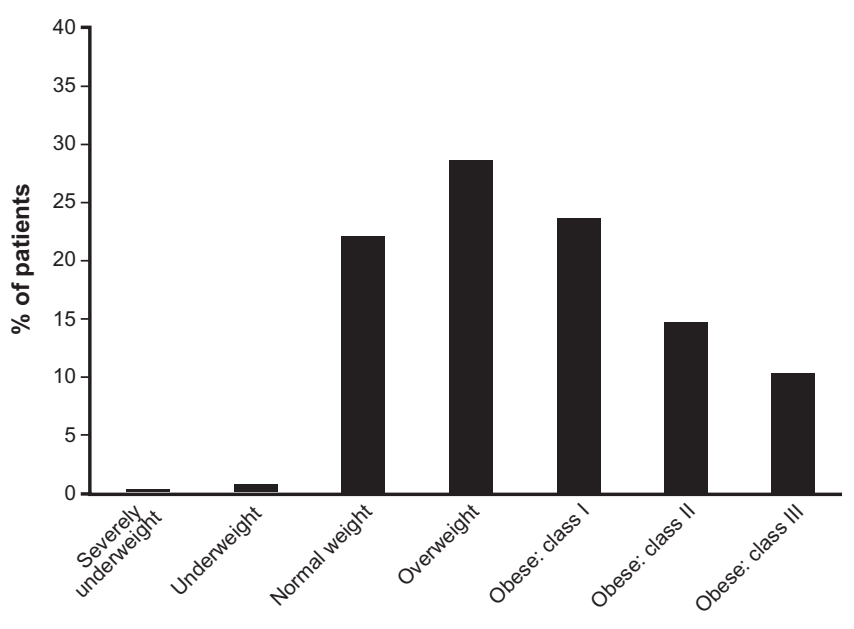

Figure I Baseline BMI in patients with fibromyalgia.

Notes: Based on World Health Organization classifications, BMI baseline strata were defined as follows: severely underweight (BMI 16 to $<17 \mathrm{~kg} / \mathrm{m}^{2}$ ), underweight (BMI 17 to $<18.5 \mathrm{~kg} / \mathrm{m}^{2}$ ), normal weight (BMI 18.5 to $<25 \mathrm{~kg} / \mathrm{m}^{2}$ ), overweight (BMI 25 to $<30 \mathrm{~kg} / \mathrm{m}^{2}$ ), obese class I (BMI 30 to $<35 \mathrm{~kg} / \mathrm{m}^{2}$ ), obese class II (BMI 35 to $\left.<40 \mathrm{~kg} / \mathrm{m}^{2}\right)$, and obese class III (BMI $\left.\geq 40 \mathrm{~kg} / \mathrm{m}^{2}\right)$. Analysis includes 3104 patients with available baseline weight data from three studies. ${ }^{19-21}$ Abbreviation: BMI, body mass index.

\section{Placebo-controlled trials and extension studies}

At 3 and 6 months in placebo-controlled trials, weight loss was significantly greater with milnacipran (about $1 \mathrm{~kg}$ ) than placebo (about $0.05 \mathrm{~kg}$, Table 1). Significant differences between milnacipran and placebo were observed at the first study visit and every subsequent visit over 6 months of treatment (Figure 2A). The percentage of patients with $\geq 5 \%$ weight loss was significantly higher with milnacipran than with placebo at 3 and 6 months $(P<0.01)$, whereas $\geq 5 \%$ weight gain was higher with placebo (Figure $3 \mathrm{~A}$ and $\mathrm{B}$ ).

Among patients receiving $\geq 12$ months of milnacipran treatment, mean weight change from beginning of the lead-in study to the final visit of the extension study was $-1.06 \mathrm{~kg}$ (Figure 2B). In this group, almost twice as many patients had a $\geq 5 \%$ weight loss than gain (Figure $3 \mathrm{~A}$ and $\mathrm{B}$ ), based on last available assessment.

\section{Long-term open-label study}

For the overall study population, mean weight change from study baseline to last available assessment was $-0.3 \mathrm{~kg}$. To account for weight changes that had occurred during lead-in studies ( 3 to 15 months) and further evaluate the effects of long-term milnacipran on body weight, additional analyses were conducted in patients who received $\geq 3$ years of open-label milnacipran treatment. In this 3-year cohort, mean weight changes from the lead-in study baseline at $12,24,30$, and 36-38 months of the open-label 
Table I Mean changes from baseline body weight in placebo-controlled milnacipran trials

\begin{tabular}{|c|c|c|c|c|}
\hline & \multirow[t]{2}{*}{ Patients, $\mathbf{n}^{\mathbf{a}}$} & \multicolumn{3}{|c|}{ LS mean changes (SEM), kg } \\
\hline & & Placebo & Milnacipran $100 \mathrm{mg} / \mathrm{day}$ & Milnacipran 200 mg/day \\
\hline \multicolumn{5}{|l|}{ Study population } \\
\hline 3 months & 2096 & $-0.06(0.13)$ & $-\mathrm{I} .14(0.13)^{\mathrm{b}}$ & $-0.97(0.16)^{b}$ \\
\hline 6 months & 1008 & $-0.04(0.25)$ & $-1.01(0.26)^{b}$ & $-0.71(0.23)^{b}$ \\
\hline \multicolumn{5}{|c|}{ Baseline BMI (3 months) } \\
\hline $\mathrm{BMI}<25$ & 711 & $0.06(0.20)$ & $-0.33(0.21)$ & $-0.44(0.25)$ \\
\hline BMI 25 to $<30$ & 886 & $0.03(0.24)$ & $-1.39(0.23)^{\mathrm{b}}$ & $-0.91(0.28)^{b}$ \\
\hline $\mathrm{BMI} \geq 30$ & 1507 & $-0.17(0.19)$ & $-\mathrm{I} .48(0.2 \mathrm{I})^{\mathrm{b}}$ & $-1.13(0.26)^{b}$ \\
\hline \multicolumn{5}{|c|}{ Treatment responders } \\
\hline 3 months & 713 & $0.01(0.20)$ & $-1.38(0.17)^{b}$ & $-1.3 \mid(0.20)^{b}$ \\
\hline 6 months & 209 & $0.50(0.68)$ & $-1.71(0.58)^{b}$ & $-\mathrm{I} .79(0.4 \mathrm{I})^{\mathrm{b}}$ \\
\hline \multicolumn{5}{|c|}{ Treatment nonresponders } \\
\hline 3 months & 1383 & $0.02(0.12)$ & $-0.86(0.14)^{b}$ & $-0.83(0.17)^{\mathrm{b}}$ \\
\hline 6 months & 303 & $0.24(0.36)$ & $-1.17(0.42)^{b}$ & $-0.82(0.32)^{b}$ \\
\hline
\end{tabular}

Notes: aAll 3-month analyses based on pooled data from studies I to 3; ${ }^{19-21}$ 6-month analysis in the study population based on studies I and 2; 19,20 6-month analyses in treatment responders and nonresponders based on study I only. ${ }^{19}$ Treatment responders defined as patients with $\geq 30 \%$ improvement in visual analog scale pain scores and a rating of "very much improved" or "much improved" on the Patient Global Impression of Change; ${ }^{\mathrm{P}}<0.05$ versus placebo.

Abbreviations: BMI, body mass index; LS, least squares; SEM, standard error of the mean.

study were $-1.16 \mathrm{~kg},-0.76 \mathrm{~kg},-0.19 \mathrm{~kg}$, and $+0.11 \mathrm{~kg}$, respectively (Figure 2C). The percentage of patients with $\geq 5 \%$ weight loss from the lead-in study baseline was relatively constant from 6 months (24.1\%) to 36-38 months $(24.1 \%$, Figure 3C). However, the percentage of patients with $\mathrm{a} \geq 5 \%$ weight gain gradually increased over time (6 months, $12.3 \%$; 36-38 months, $28.6 \%$ ).

At each visit in this long-term, open-label study, Pearson correlations $(r)$ between changes in weight and visual analog scale pain scores were very low (range, -0.05 to +0.13 ) with no significant $P$ values, indicating no or minimal association between weight change and pain improvements.

\section{Analyses by baseline BMI and treatment response}

Milnacipran-treated patients lost weight regardless of baseline BMI, with significant differences between milnacipran and placebo in overweight and obese patients at 3 months (Table 1). No significant differences between milnacipran and placebo were found in underweight/normal weight patients, possibly due to the smaller size of this subgroup. In addition, overweight and obese patients had greater mean weight losses with milnacipran than underweight/normal weight patients, but statistical comparisons among these three subgroups were not performed.

Weight loss with milnacipran was also observed regardless of treatment response, with significant differences between milnacipran and placebo at 3 and 6 months in both treatment responders and nonresponders (Table 1). However, at both time points, mean weight loss was greater in treatment responders than nonresponders; this difference was significant for milnacipran $100 \mathrm{mg} /$ day at 3 months $(P=0.02)$ with a trend for milnacipran $200 \mathrm{mg} /$ day.

\section{Nausea and weight-related adverse events}

Nausea was the most common treatment-emergent adverse event in the placebo-controlled trials. ${ }^{19-21}$ To explore whether weight loss with milnacipran was attributable to nausea, nausea rates were analyzed in patients who lost and did not lose weight in these studies. In the 3-month analysis, the proportion of patients who had experienced nausea was significantly lower in milnacipran-treated patients who lost weight (33.9\%) than in patients who did not $(40.5 \% ; P=0.02)$. In the 6 -month analysis, the proportion of patients with nausea remained lower in patients who lost weight (33.0\%) than those who did not $(39.7 \%)$, but the difference was not significant.

Weight-related adverse events (ie, decreased appetite, increased appetite, anorexia, decreased weight, and increased weight) occurred in $<2 \%$ of patients receiving milnacipran or placebo for 6 months in placebo-controlled trials. Discontinuations due to these weight-related adverse events were also low $(\leq 0.25 \%)$ in the placebo-controlled trials. Weight-related adverse events occurred in $<3.5 \%$ of patients in the extension studies ( $\geq 12$ months) and in the long-term, open-label study.

\section{Discussion}

Clinically relevant weight changes ( $\geq 5 \%$ change from baseline) were evaluated in this largely obese/overweight 
A

Placebo-controlled studies
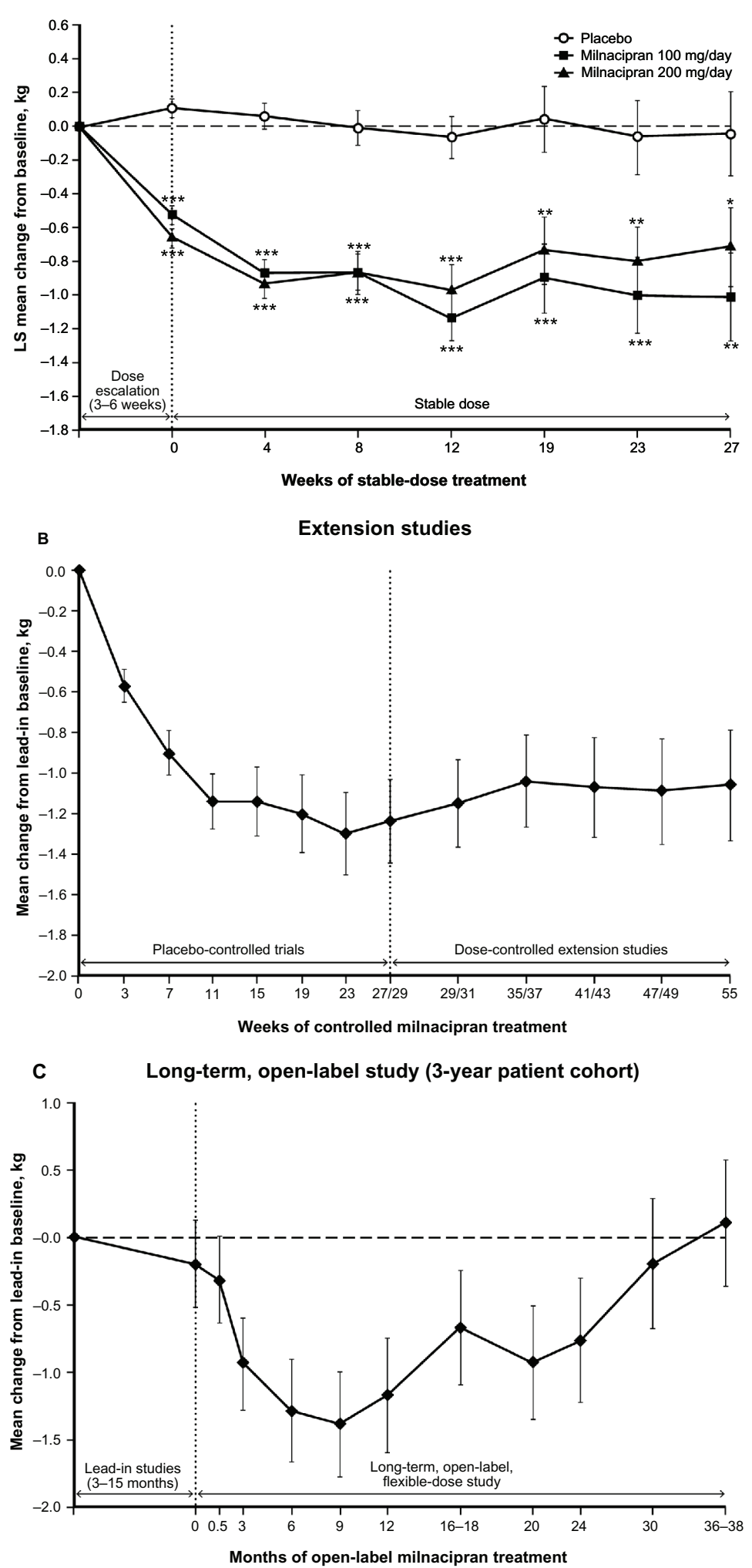

Figure 2 Body weight changes with standard errors by study visit among (A) patients in randomized, placebo-controlled studies (baseline, $n=3104 ; 3$ months [ 12 weeks], $\mathrm{n}=$ 2096; 6 months [27 weeks], $\mathrm{n}=1008$ ); (B) patients in extension studies receiving $\geq 12$ months of continuous milnacipran treatment $(\mathrm{n}=354)$; and (C) patients receiving $\geq 3$ years of milnacipran treatment in a long-term, open-label study $(n=220)$.

Notes: Analyses are based on observed cases, with least squares mean changes from baseline shown for placebo-controlled trials and mean changes from lead-in study baseline shown for extension studies and the long-term, open-label study. For placebo-controlled trials, data for weeks $0-12$ are from three studies ${ }^{19-21}$ and data for weeks $19-27$ are from two studies. ${ }^{19,20}$ The last visit for study I was at week 27 , and the last visit for study 2 was at week 29 . $* P<0.05 ; * * P<0.01 ; * * * P<0.00$ I versus placebo. Abbreviation: LS, least squares. 

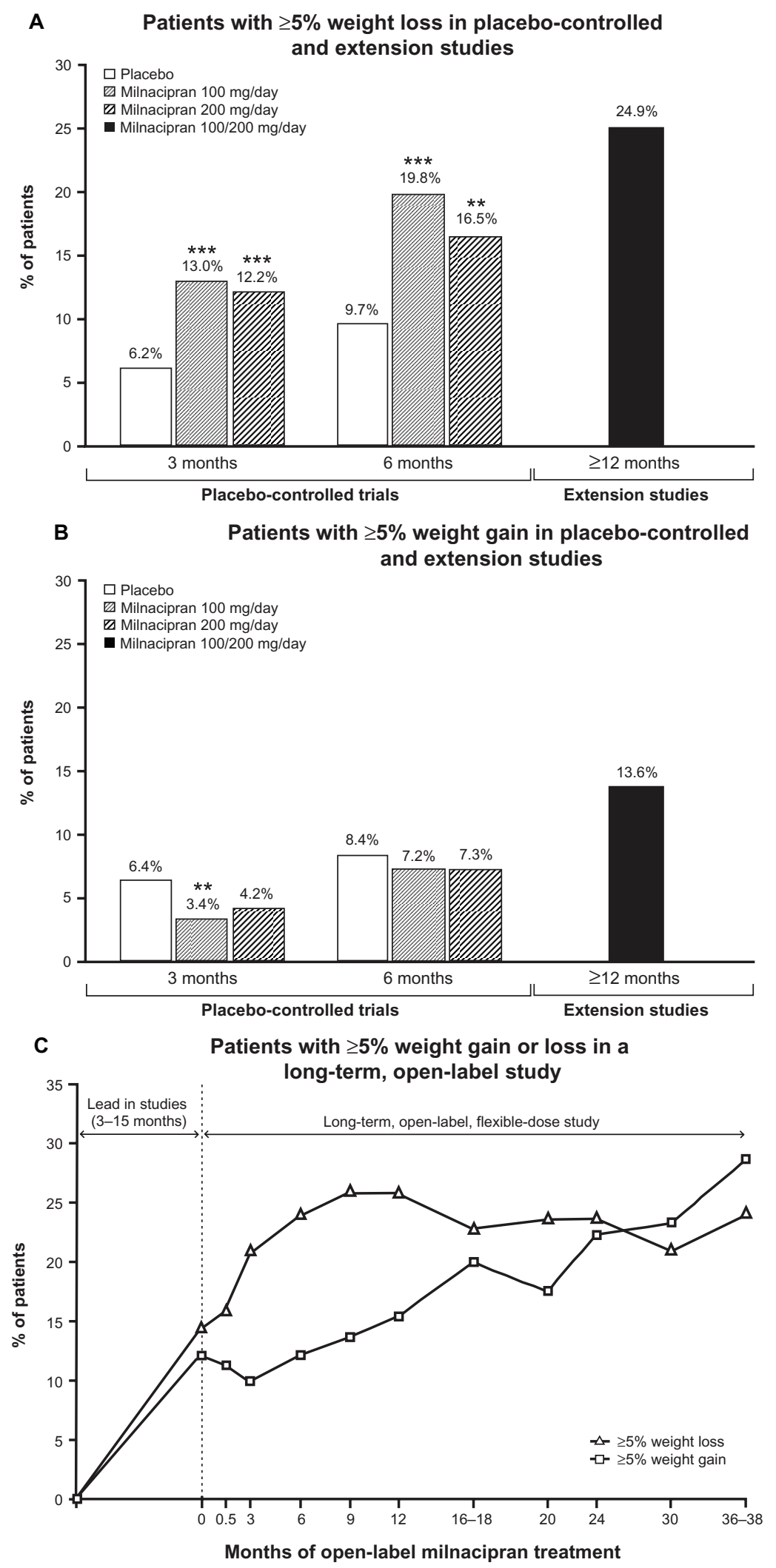

Figure 3 Percentage of patients with (A) $\geq 5 \%$ weight loss at 3, 6, and $\geq 12$ months; (B) $\geq 5 \%$ weight gain at 3, 6, and $\geq 12$ months; and (C) $\geq 5 \%$ weight loss or gain from lead-in patients who received 3 years of treatment in the long-term, open-label study.

Notes: The 3-month analyses $(n=2096)$ and 6-month analyses $(n=1008)$ included patients who participated in a placebo-controlled trial of milnacipran. The $\geq 12$-month analyses $(n=354)$ included patients who received milnacipran during a placebo-controlled trial and extension study, and are based on weight changes from the lead-in study baseline. Analyses for the 3-year cohort $(n=220)$ are based on weight changes from baseline of the first lead-in study prior to the long-term, open-label study. $* * P<0.01$; $* * * P<0.001$ versus placebo. 
patient population. At 3 and 6 months in placebo-controlled trials, the percentage of patients with clinically relevant weight loss was approximately twice as high with milnacipran than placebo (Figure 3A); weight gain was more common with placebo than milnacipran (Figure 3B). Among patients in extension studies who received $\geq 12$ months of milnacipran treatment, clinically relevant weight loss $(24.9 \%)$ was more common than weight gain (13.6\%). In the 3-year cohort in the open-label study, the percentage of patients with $\geq 5 \%$ weight loss remained relatively constant over time $(24.1 \%$ at 6 months, $24.1 \%$ at $36-38$ months), whereas the percentage of patients with $\geq 5 \%$ weight gain increased over time (12.3\% at 6 months, $28.6 \%$ at $36-38$ months). These findings suggest that a subset of patients with fibromyalgia may maintain modest weight loss with milnacipran over long periods of time, although analyses of weight changes within individual patients would be needed to explore this possibility.

Regarding group differences in mean weight changes, the pooled analysis of three placebo-controlled studies showed significant mean weight loss in milnacipran-treated patients at 3 and 6 months (Table 1), with similar weight loss $(-1.06 \mathrm{~kg})$ found in patients who participated in extension studies and received $\geq 12$ months of continuous milnacipran treatment.

Among all patients participating in the long-term, openlabel study, mean change from study baseline to the last available assessment was $-0.3 \mathrm{~kg}$. However, these results do not reflect weight changes that occurred during placebocontrolled and extension studies that led into the open-label study. In patients receiving $\geq 3$ years of treatment in the open-label study (in addition to 3-15 months of prior study treatment), mean decreases from lead-in study baseline were found at 12 and 24 months $(-1.16 \mathrm{~kg}$ and $-0.76 \mathrm{~kg}$, respectively), with mean changes drifting back to baseline at 30 months $(-0.19 \mathrm{~kg})$ and the final study visit at $36-38$ months $(+0.11 \mathrm{~kg})$.

Nausea was the most commonly reported adverse event with milnacipran (studies 1 to 3: placebo, $20.6 \% ; 100 \mathrm{mg} /$ day, $35.5 \% ; 200 \mathrm{mg} /$ day, $40.1 \%) .{ }^{19-21}$ In the present analysis, nausea rates were significantly lower in patients who lost weight than in patients who did not lose weight, suggesting that nausea did not contribute to weight loss.

Because patients who respond to milnacipran may be more likely to continue treatment, analyses were also conducted in treatment responders and nonresponders. In placebo-controlled studies, the proportion of treatment responders (patients with simultaneous improvements in pain and global status) at 3 and 6 months was significantly higher with milnacipran ( $39 \%$ to $46 \%$ ) than placebo ( $25 \%$ to $28 \%, P<0.05) .{ }^{19-21}$ In the present analysis, significant mean weight loss was found with milnacipran versus placebo regardless of responder status ( 3 and 6 months, $P<0.05$ ). These preliminary results, along with the lack of correlation found between changes in weight and pain in patients receiving $\geq 3$ years of open-label milnacipran treatment, suggest that weight loss with milnacipran was not completely dependent on improvements in pain or other fibromyalgia symptoms. However, weight loss was approximately $45 \%$ $120 \%$ greater in treatment responders than in nonresponders. Additional correlations between weight, pain, and other potentially relevant factors, such as physical functioning, would be needed to characterize further the relationship between milnacipran efficacy and weight change.

Drug-induced weight gain is just one factor to consider when developing a treatment plan, but it may be an important issue for patients who are concerned about weight. ${ }^{15}$ Additionally, clinicians should consider a multidisciplinary treatment plan in patients with fibromyalgia who are overweight or obese..$^{30} \mathrm{~A}$ plan that includes medication to manage pain and other disruptive symptoms along with mild-tomoderate aerobic exercise ${ }^{31,32}$ and cognitive behavioral therapy ${ }^{33,34}$ may benefit many patients with fibromyalgia. Although the evidence in patients with fibromyalgia is limited, dietary programs may also benefit some patients. ${ }^{35}$

\section{Limitations}

This was a post hoc analysis and the studies included were not prospectively designed to measure weight change as a primary outcome. The analyses were based on a clinical study population, which primarily included women (about 95\%) with moderate or severe baseline pain. Thus, any interpretation regarding gender differences or disease severity would be limited. In addition, no analyses were conducted in patients with comorbidities that may complicate weight problems, such as diabetes or hypertension, nor were any analyses adjusted for familial or environmental factors that could affect weight. ${ }^{12}$ Moreover, patients with major depressive disorder were excluded from the studies. ${ }^{19-21}$ Thus, no conclusions about the effects of milnacipran in these subsets of patients can be drawn. Conclusions regarding the effects of nausea on weight may also be limited given that the analysis did not differentiate between transient and persistent nausea. Although the majority of nausea episodes $(>60 \%)$ observed in the placebo-controlled studies were resolved within 3 weeks of onset, ${ }^{21,36}$ some patients with ongoing nausea may have altered their eating habits which in turn may have 
affected their weight. Finally, patients with fibromyalgia often require multiple medications and the present analysis did not explore the effects of milnacipran on body weight in patients taking concomitant medications that may contribute to weight changes. Although centrally acting medications used to treat fibromyalgia symptoms were prohibited in the placebo-controlled and extension studies, some drugs associated with weight change were allowed.

\section{Conclusion}

The majority (77\%) of patients with fibromyalgia in placebocontrolled milnacipran trials were classified as overweight or obese (BMI $\geq 25 \mathrm{~kg} / \mathrm{m}^{2}$ ). In light of these potential weight problems, the effects of medication on body weight may need to be considered when managing these patients. Overall, mean weight changes observed in placebo-controlled and extension studies suggested that treatment with milnacipran for $\geq 12$ months was not associated with weight gain. In addition, no mean weight gain was found in patients receiving up to 30 months of milnacipran treatment in a longterm, open-label study, with mean weight drifting to above baseline values in patients receiving $\geq 3$ years of treatment. Analyses of data at 3 and 6 months indicate that the effects of milnacipran on body weight are observed regardless of treatment response, although weight loss may be greater in treatment responders. Patients with weight problems may benefit from a multidisciplinary treatment approach.

\section{Acknowledgments}

The authors thank Yimin Ma at Forest Research Institute Inc, for conducting some of the statistical analyses. They also thank Mildred Bahn at Prescott Medical Communications Group for writing assistance supported by Forest Laboratories Inc.

\section{Disclosure}

LMA has received consulting fees and/or honoraria from Grünenthal, Forest Laboratories Inc, Daiichi Sankyo $(<\$ 10,000$ each) and Pfizer Inc $(>\$ 10,000)$. She has received research support from Eli Lilly and Company, Cypress Bioscience Inc, Boehringer Ingelheim GmBH, Forest Laboratories Inc, Novartis AG, Takeda Pharmaceutical Company Ltd, and Pfizer Inc. RHP and WC are employees of Forest Research Institute Inc, a subsidiary of Forest Laboratories Inc. MRH is a former employee of Cypress Bioscience Inc.

\section{References}

1. Bennett RM. Clinical manifestations and diagnosis of fibromyalgia. Rheum Dis Clin North Am. 2009;35(2):215-232.
2. Arnold LM, Clauw DJ, McCarberg BH; FibroCollaborative. Improving the recognition and diagnosis of fibromyalgia. Mayo Clin Proc. 2011;86(5):457-464.

3. Lachaine J, Beauchemin C, Landry PA. Clinical and economic characteristics of patients with fibromyalgia syndrome. Clin J Pain. 2010;26(4):284-290.

4. Yunus MB, Arslan S, Aldag JC. Relationship between body mass index and fibromyalgia features. Scand J Rheumatol. 2002;31(1):27-31.

5. Bennett RM, Jones J, Turk DC, Russell IJ, Matallana L. An internet survey of 2,596 people with fibromyalgia. BMC Musculoskelet Disord. 2007;8:27.

6. Neumann L, Lerner E, Glazer Y, Bolotin A, Shefer A, Buskila D. A cross-sectional study of the relationship between body mass index and clinical characteristics, tenderness measures, quality of life, and physical functioning in patients with fibromyalgia. Clin Rheumatol. 2008;27(12):1543-1547.

7. Okifuji A, Bradshaw DH, Olson C. Evaluating obesity in fibromyalgia: neuroendocrine biomarkers, symptoms, and functions. Clin Rheumatol. 2009;28(4):475-478.

8. Okifuji A, Donaldson GW, Barck L, Fine PG. Relationship between fibromyalgia and obesity in pain, function, mood, and sleep. $J$ Pain. 2010;11(12):1329-1337.

9. Kim CH, Luedtke CA, Vincent A, Thompson JM, Oh TH. The association of body mass index with symptom severity and quality of life in patients with fibromyalgia. Arthritis Care Res (Hoboken). 2012;64(2):222-228.

10. Salaffi F, Sarzi-Puttini P, Girolimetti R, Atzeni F, Gasparini S, Grassi W. Health-related quality of life in fibromyalgia patients: a comparison with rheumatoid arthritis patients and the general population using the SF-36 health survey. Clin Exp Rheumatol. 2009;27(5 Suppl 56): S67-S74.

11. Ursini F, Naty S, Grembiale RD. Fibromyalgia and obesity: the hidden link. Rheumatol Int. 2011;31(11):1403-1408.

12. Wright LJ, Schur E, Noonan C, Ahumada S, Buchwald D, Afari N. Chronic pain, overweight, and obesity: findings from a communitybased twin registry. J Pain. 2010;11(7):628-635.

13. Hainer V, Kabrnova K, Aldhoon B, Kunesova M, Wagenknecht M. Serotonin and norepinephrine reuptake inhibition and eating behavior. Ann N Y Acad Sci. 2006;1083:252-269.

14. Malone M. Medications associated with weight gain. Ann Pharmacother. 2005;39(12):2046-2055.

15. Ness-Abramof R, Apovian CM. Drug-induced weight gain. Drugs Today (Barc). 2005;41(8):547-555.

16. Arnold LM, Russell IJ, Diri EW, et al. A 14-week, randomized, doubleblinded, placebo-controlled monotherapy trial of pregabalin in patients with fibromyalgia. J Pain. 2008;9(9):792-805.

17. Mease PJ, Russell IJ, Arnold LM, et al. A randomized, double-blind, placebo-controlled, phase III trial of pregabalin in the treatment of patients with fibromyalgia. J Rheumatol. 2008;35(3):502-514.

18. Gaynor P, McCarberg B, Zheng W, Shoemaker S, Duenas H. Weight change with long-term duloxetine use in chronic painful conditions: an analysis of 16 clinical studies. Int J Clin Pract. 2011;65(3): 341-349.

19. Mease PJ, Clauw DJ, Gendreau RM, et al. The efficacy and safety of milnacipran for the treatment of fibromyalgia. Results of a randomized, double-blind, placebo-controlled trial [published correction appears in J Rheumatol. 2009;36(3):661]. J Rheumatol. 2009;36(2):398-409.

20. Clauw DJ, Mease PJ, Palmer RH, Gendreau RM. Milnacipran for the treatment of fibromyalgia in adults: a 15 -week, multicenter, randomized, double-blind, placebo-controlled, multiple-dose clinical trial [published correction appears in Clin Ther. 2009;31(2):446]. Clin Ther. 2008;30(11):1988-2004.

21. Arnold LM, Gendreau RM, Palmer RH, Gendreau JF, Wang Y. Efficacy and safety of milnacipran $100 \mathrm{mg} /$ day in patients with fibromyalgia: results of a randomized, double-blind, placebo-controlled trial. Arthritis Rheum. 2010;62(9):2745-2756. 
22. Goldenberg DL, Clauw DJ, Palmer RH, Mease P, Chen W, Gendreau RM. Durability of therapeutic response to milnacipran treatment for fibromyalgia. Results of a randomized, double-blind, monotherapy 6-month extension study. Pain Med. 2010;11(2):180-194.

23. Ferrera R, Palmer R, Chen W, Gendreau R. Improvements in fibromyalgia symptoms are sustained for 1 year with milnacipran treatment: results from 2 double-blind, dose-controlled extension studies [Abstract]. J Pain. 2009;10(4 Suppl 1):S60.

24. Arnold L, Spera A, Baldecchi A, Wang Y. A three-year, open-label, flexible-dosing study of milnacipran for the treatment of fibromyalgia. [Abstract]. J Pain. 2011;12(4 Suppl 2):S22.

25. Wolfe F, Smythe HA, Yunus MB, et al. The American College of Rheumatology 1990 Criteria for the Classification of Fibromyalgia. Report of the Multicenter Criteria Committee. Arthritis Rheum. 1990;33(2):160-172.

26. World Health Organization. Obesity and overweight. Fact sheet No 311; updated March 2011. Available from: http://www.who.int/mediacentre/ factsheets/fs311/en/. Accessed August 30, 2012.

27. Field AE, Wing RR, Manson JE, Spiegelman DL, Willett WC. Relationship of a large weight loss to long-term weight change among young and middle-aged US women. Int J Obes Relat Metab Disord. 2001;25(8):1113-1121.

28. Pasanisi F, Contaldo F, de Simone G, Mancini M. Benefits of sustained moderate weight loss in obesity. Nutr Metab Cardiovasc Dis. 2001;11(6): $401-406$

29. US Food and Drug Administration. Guidance for Industry. Developing products for weight management: draft guidance. Feb 2007. Available from: http://www.fda.gov/downloads/Drugs/ GuidanceComplianceRegulatoryInformation/Guidances/ucm071612. pdf. Accessed August 30, 2012.
30. Shapiro JR, Anderson DA, Danoff-Burg S. A pilot study of the effects of behavioral weight loss treatment on fibromyalgia symptoms. J Psychosom Res. 2005;59(5):275-282.

31. Haüser W, Klose P, Langhorst J, et al. Efficacy of different types of aerobic exercise in fibromyalgia syndrome: a systematic review and meta-analysis of randomised controlled trials. Arthritis Res Ther. 2010;12(3):R79

32. Kelley GA, Kelley KS, Hootman JM, Jones DL. Exercise and global well-being in community-dwelling adults with fibromyalgia: a systematic review with meta-analysis. BMC Public Health. 2010;10:198.

33. Bennett R, Nelson D. Cognitive behavioral therapy for fibromyalgia. Nat Clin Pract Rheumatol. 2006;2(8):416-424.

34. Rapoport L, Clark M, Wardle J. Evaluation of a modified cognitivebehavioural programme for weight management. Int J Obes Relat Metab Disord. 2000;24(12):1726-1737.

35. Li S, Micheletti R. Role of diet in rheumatic disease. Rheum Dis Clin North Am. 2011;37(1):119-133.

36. Geisser ME, Palmer RH, Gendreau RM, Wang Y, Clauw DJ. A pooled analysis of two randomized, double-blind, placebo-controlled trials of milnacipran monotherapy in the treatment of fibromyalgia. Pain Pract. 2011;11(2):120-131.
International Journal of General Medicine

\section{Publish your work in this journal}

The International Journal of General Medicine is an international, peer-reviewed open-access journal that focuses on general and internal medicine, pathogenesis, epidemiology, diagnosis, monitoring and treatment protocols. The journal is characterized by the rapid reporting of reviews, original research and clinical studies across all disease areas.

\section{Dovepress}

A key focus is the elucidation of disease processes and management protocols resulting in improved outcomes for the patient.The manuscript management system is completely online and includes a very quick and fair peer-review system. Visit http://www.dovepress.com/ testimonials.php to read real quotes from published authors. 